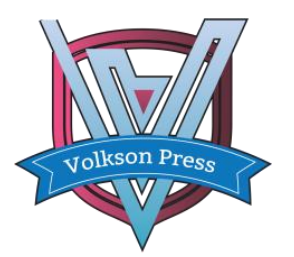

Contents List available at VOLKSON PRESS

Mechanical and Control Engineering (MCE)

DOI : http://doi.org/10.26480/wsmce.01.2017.18.20

\title{
CHARACTERIZATION OF THE UV - VISIBLE ABSORPTION SPECTRA OF COMMONLY USED PHOTOINITIATORS
}

\author{
Bu Rongxia ${ }^{1}$, Luo Shiyong1' Xu Wencai ${ }^{1}$,Meng Ruiqiang² ${ }^{1} \mathrm{He} \mathrm{Di}^{2}$, Mao Kelin², Huang Jiangwei², Xiao Yong², Li Caichang ${ }^{2}$ \\ ${ }_{1}^{1}$ School of Printing and Packaging Engineering,Beijing Institute of Graphic Communication, Xinghua Street ,Beijing, China \\ ${ }^{2}$ Guangxi Zhenlong Color Printing Packing Co., Ltd, Fuchuan, Guangxi, China \\ *Corresponding Author Email: luoshiyong@bigc.edu.cn
}

This is an open access article distributed under the Creative Commons Attribution License, which permits unrestricted use, distribution, and reproduction in any medium, provided the original work is properly cited

\section{ARTICLE DETAILS}

\section{Article History:}

Received 02 october 2017 Accepted 06 october 2017 Available online 11 november 2017

Keywords:

photoinitiator, spectrophotometer, absorption spectrosco $\begin{array}{lll}\text { performance, food } & \text { safety }\end{array}$

\section{ABSTRACT}

UV-LED curing has the advantages of energy saving and no ozone, mercury pollution has become one of the recently developed green printing technology.The photoinitiator used to meet the requirements of food packaging materials, but also in the LED issued by the central wavelength of $385 \mathrm{~nm}$ or $395 \mathrm{~nm}$ light absorption can stimulate the photopolymerization.In this paper, the absorption spectra of 12 kinds of photoinitiators, such as TPO, BDK, ITX, DETX, 819,784, TPO-L,127,369,MBF,199,796,were characterized by UV-Vis spectrophotometer. Prepared UV-LED curing varnish,The performance of the photoinitiator was analyzed.According to the requirements of food safety regulations, the photoinitiators which could be used for UV-LED curing were obtained TPO, TPO-L and $819 .{ }^{\text {. }}$

\section{Introduction}

Photoinitiators, also known as photosensitizers or photocuring agents, are substances that absorb radiant energy and undergo chemical changes to produce reactive intermediates that initiate polymerization.Can lead to monomer, oligomer and polymer unsaturated double bond crosslinking curing [1].The photoinitiator (PI) absorbs the energy under the ultraviolet light and undergoes an electronic transition, which changes from the ground state to the excited state (PI ${ }^{*}$ ) and then decomposes into free radicals;Radicals react with the other components (M) of the photoluminescent groups that contain photocurable groups and continue to polymerize to form chain-like growth, accompanied by the transfer and termination of free radicals in the growing chain [2]. Photoinitiation systems are either one-component (photoinitiator) or some twocomponent or multi-component (photoinitiator/ additive),Photoinitiator is the key factor to control the photopolymerization process. The efficiency of photoinitiator is directly determined by its light absorption (absorption wavelength, molar extinction coefficient) and reactivity [3]

UV-LED curing was developed on the basis of UV curing , It is a technology that can be rapidly cured under the LED central wavelength of $385 \mathrm{~nm}$ or $395 \mathrm{~nm}$,which has the advantages of energy saving, ozone-free and mercury pollution [4].UV-LED curing varnish or ink is coated, printed, LED radiation curing into a film, in which some of the remaining photoinitiators may be through chemical migration or physical contact migration from the food package to the food inside the package, Thus polluting the products in the package, causing potential harm to human health.November 23, 2015 Switzerland Introduces Two Catalog Lists of Regulations Concerning Food Packaging Materials (RS 817.023.21) , List A refers to materials that are suggested for using in food packaging, and List B refers to some materials that can be used but have not yet been fully validated.At present, Europe and the United States refer to the contents of the Swiss regulations and Nestle's norms for the material requirements of food printing. Both of these requirements need to be met at the same time [5]. China Tobacco Corporation industry standard YQ69-2015 "cigarette and box packaging paper safety and health requirements" clearly defines the limit of the photo-initiator residue after printing and banned photoinitiator catalog.These regulations make it clear that photoinitiators in materials used in food packaging materials must meet the requirements [6]. In this paper, the commonly used initiator in food packaging materials for absorption spectroscopy test, expecting to obtain a photoinitiator which meets the requirements of food packaging materials and which can be excited under the illumination of LED.

\section{EXPERIMENTS}

\subsection{Experimental photoinitiators}

The photoinitiator used in this experiment was purchased from Shanghai Guangyi Chemical Co., Ltd., Guangzhou Lihou Trading Co., Ltd. and Tianjin Jiuri Chemical Co., Ltd.The following Table 1 shows the various properties of the photoinitiators.

Table 1: Different properties of different photoinitiators

\begin{tabular}{|c|c|c|c|c|c|}
\hline product name & Chemical type & Exterior & CAS No. & $\begin{array}{l}\text { Molecular } \\
\text { weight }\end{array}$ & $\begin{array}{l}\text { Absorption } \\
\text { Melting wavelength } \\
\text { point } \quad \text { (in methanol } \\
\text { solution) }\end{array}$ \\
\hline Irgacure 127 & $\alpha$-hydroxy ketones & $\begin{array}{l}\text { White } \\
\text { powder }\end{array}$ & $\begin{array}{l}474510- \\
57-1\end{array}$ & 340.4 & $82-90^{\circ} \mathrm{C} 259 \mathrm{~nm}$ \\
\hline Irgacure TPO & Monoacylphosphine & $\begin{array}{l}\text { Light yellow } \\
\text { powder }\end{array}$ & $\begin{array}{l}75980- \\
60-8\end{array}$ & 418.5 & $\begin{array}{r}88-92^{\circ} \mathrm{C} 295 \mathrm{~nm}, 368 \mathrm{~nm}, \\
380 \mathrm{~nm}, 393 \mathrm{~nm}\end{array}$ \\
\hline Irgacure 819 & Diacyl phosphine & $\begin{array}{l}\text { Light yellow } \\
\text { powder }\end{array}$ & $\begin{array}{l}162881- \\
26-7\end{array}$ & 418.5 & $\begin{array}{l}127- \\
133^{\circ} \mathrm{C}\end{array} \quad 295 \mathrm{~nm}, 370 \mathrm{~nm}$ \\
\hline Irgacure 369 & $\alpha$-hydroxy ketones & $\begin{array}{l}\text { Light yellow } \\
\text { powder }\end{array}$ & $\begin{array}{l}119313- \\
12-1\end{array}$ & 366.5 & $\begin{array}{l}110- \\
114^{\circ} \mathrm{C}\end{array} 233 \mathrm{~nm}, 324 \mathrm{~nm}$ \\
\hline Irgacure MBF & Phenyl ethanediamide & $\begin{array}{l}\text { Transparent } \\
\text { yellowish } \\
\text { liquid }\end{array}$ & $\begin{array}{l}15206- \\
55-0\end{array}$ & 164.2 & $17^{\circ} \mathrm{C} \quad 255 \mathrm{~nm}, 300 \mathrm{~nm}$ \\
\hline Irgacure 784 & Metallic compounds & $\begin{array}{l}\text { Orange } \\
\text { powder }\end{array}$ & $\begin{array}{l}125051- \\
32-3\end{array}$ & 534.4 & $\begin{array}{l}160- \\
170^{\circ} \mathrm{C}\end{array} \quad 520 \mathrm{~nm}$ \\
\hline Easepi 199 & Benzophenone derivatives & $\begin{array}{l}\text { White } \\
\text { powder }\end{array}$ & $\begin{array}{l}\text { Patent } \\
\text { Protection }\end{array}$ & $\begin{array}{l}\text { A small } \\
\text { molecule type } \\
\text { photoinitiator }\end{array}$ & $82-84^{\circ} \mathrm{C} 220 \mathrm{~nm}, 280 \mathrm{~nm}$ \\
\hline $\begin{array}{l}\text { Photoinitiator } \\
\text { BDK }\end{array}$ & $\begin{array}{l}\text { Benzoin dimethyl } \\
\text { ether }\end{array}$ & $\begin{array}{l}\text { White } \\
\text { crystalline } \\
\text { solid }\end{array}$ & $\begin{array}{l}{[24650-} \\
42-8]\end{array}$ & 256.3 & $64-66^{\circ} \mathrm{C}_{325 \mathrm{~nm}, 255 \mathrm{~nm},}^{220 \mathrm{n}}$ \\
\hline $\begin{array}{l}\text { Photoinitiator } \\
\text { ITX }\end{array}$ & 2-isopropylthioxanthone & $\begin{array}{l}\text { Light yellow } \\
\text { crystal }\end{array}$ & $\begin{array}{l}5495-84- \\
1\end{array}$ & 254.3468 & $74-76^{\circ} \mathrm{C} 250 \mathrm{~nm}-390 \mathrm{~nm}$ \\
\hline
\end{tabular}




\begin{tabular}{|c|c|c|c|c|c|}
\hline $\begin{array}{l}\text { Photoinitiator } \\
\text { DETX }\end{array}$ & 2,4-diethyl thioxanthone & $\begin{array}{l}\text { Yellow } \\
\text { powdery } \\
\text { solid }\end{array}$ & $\begin{array}{l}82799- \\
44-8\end{array}$ & 268.37 & $70-75^{\circ} \mathrm{C} 261 \mathrm{~nm}, 385 \mathrm{~nm}$ \\
\hline $\begin{array}{l}\text { Photoinitiator } \\
\text { TPO-L }\end{array}$ & 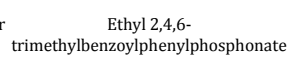 & $\begin{array}{l}\text { Yellow } \\
\text { etransparent } \\
\text { liquid }\end{array}$ & $\begin{array}{l}84434- \\
11-7\end{array}$ & 316.33 & $299 \mathrm{~nm}, 366 \mathrm{~nm}$ \\
\hline $\begin{array}{l}\text { Photoinitiator } \\
796\end{array}$ & & $\begin{array}{l}\text { Light yellow } \\
\text { powder }\end{array}$ & $\begin{array}{l}v \text { Patent } \\
\text { Protection }\end{array}$ & & $260 \mathrm{~nm}, 335 \mathrm{~nm}$ \\
\hline
\end{tabular}

\section{UV - visible light absorption spectroscopy test}

The experimental instrument is UV - visible spectrophotometer, model UV-2501PC,The photoinitiator solution was prepared by dissolving various photoinitiators selected in the acetonitrile solvent at a mass fraction of $0.01 \%$ at room temperature. Respectively, take appropriate photoinitiator solution and acetonitrile solvent in a quartz cuvette,In contrast to the acetonitrile solution, the UV-vis spectrophotometer was used for testing to determine the UV absorption spectra of different photoinitiators. For the photoinitiators which may be used for UV-LED curing, the varnish was prepared and the light stability and curing property of the varnish were analyzed.

\section{RESULTS AND DISCUSSIONS}

Figure 1 and Figure 2 show the UV absorption spectra of photoinitiators TPO and TPO-L, respectively.

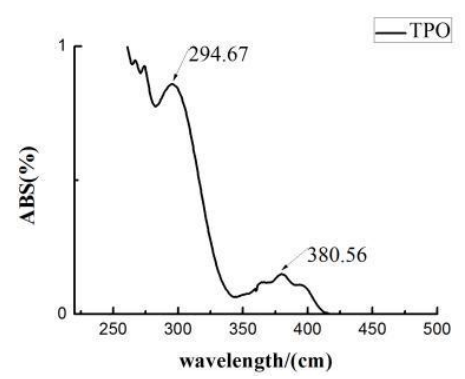

Figure 1: Ultraviolet Absorption Spectra of Photoinitiator TPO

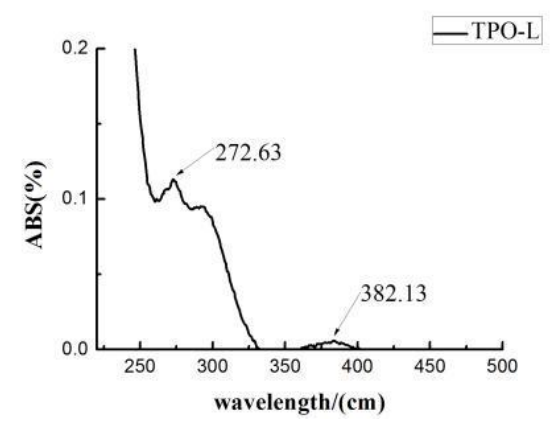

Figure 2: Ultraviolet Absorption Spectra of Photoinitiator TPO - L

It can be seen from Figure 1 and Figure 2 that the absorption peak of photoinitiator TPO is about $290 \mathrm{~nm}$ and about $380 \mathrm{~nm}$, while the absorption peak of photoinitiator TPO-L is about $272 \mathrm{~nm}$,Comparing the two curves, it can be seen that the absorption intensity of TPO is greater than the absorption intensity of TPO-L.Because TPO-L is a liquid that contains less components than TPO, the absorption is lower than that of TPO.

Figure 3-Figure 12 show UV absorbance spectra of photoinitiators 127, MBF, 819, 199, 369, 784, 796, BDK, DETX and ITX, respectively.

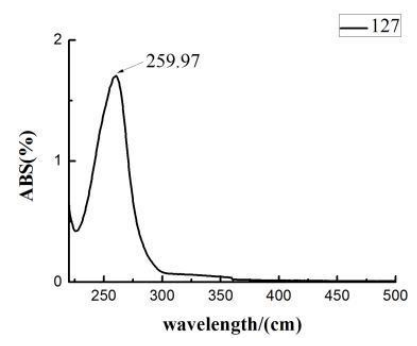

Figure 3: Ultraviolet Absorption Spectra of Photoinitiator 127

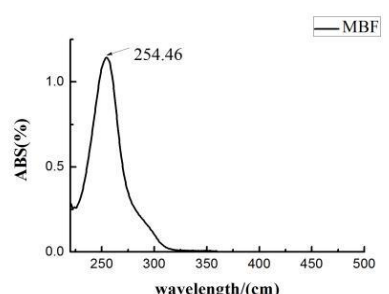

Figure 4: Ultraviolet Absorption Spectra of Photoinitiator MBF

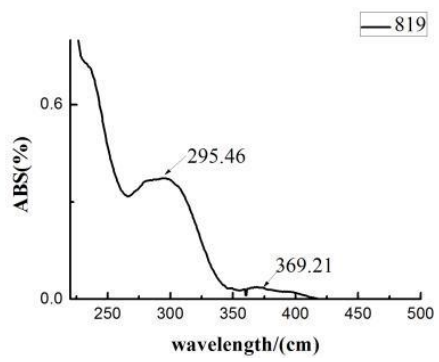

Figure 5: Ultraviolet Absorption Spectra of Photoinitiator 819

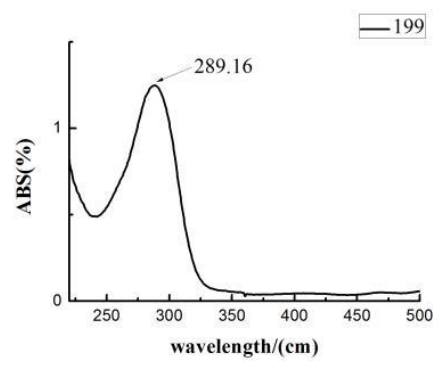

Figure 6: Ultraviolet Absorption Spectra of Photoinitiator 199

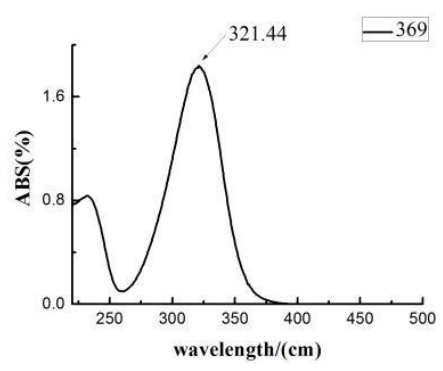

Figure 7: Ultraviolet Absorption Spectra of Photoinitiator 369

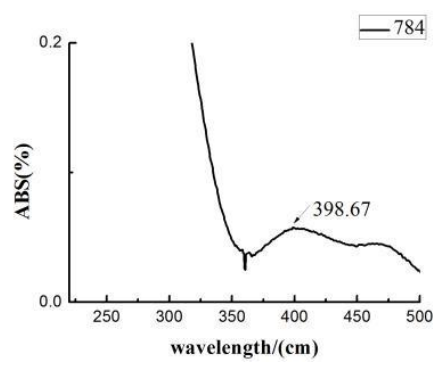

Figure 8: Ultraviolet Absorption Spectra of Photoinitiator 784 


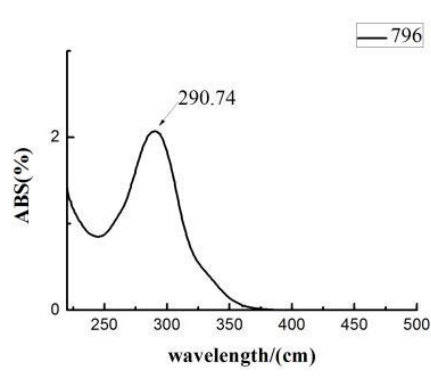

Figure 9: Ultraviolet Absorption Spectra of Photoinitiator 796

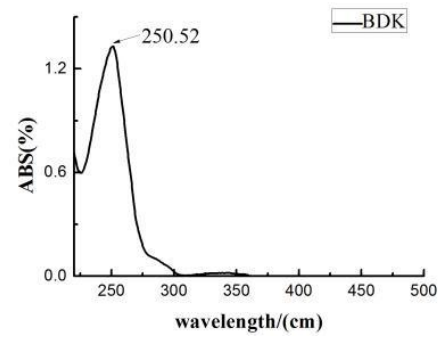

Figure 10: Ultraviolet Absorption Spectra of Photoinitiator BDK

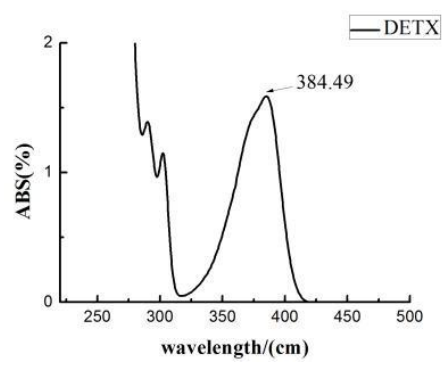

Figure 11: Ultraviolet Absorption Spectra of Photoinitiator DETX

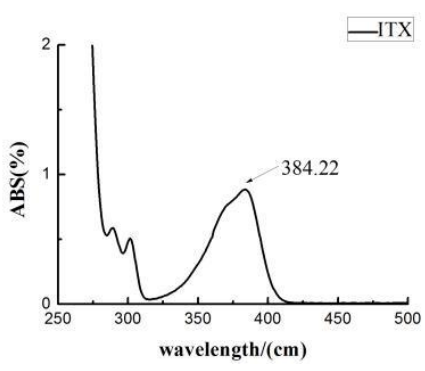

Figure 12: Ultraviolet Absorption Spectra of Photoinitiator ITX

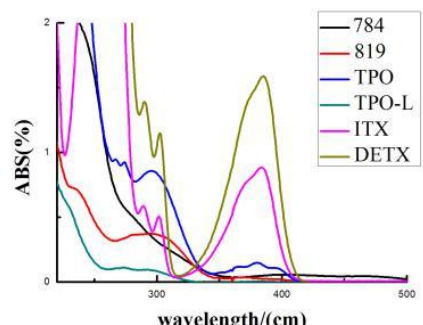

Figure 13: Ultraviolet Absorption Spectra of Six Photoinitiators

It can be seen from Figure 13 that there are 819, TPO, TPO-L, ITX, 784 and DETX with wavelengths between 360 and $400 \mathrm{~nm}$.Among them, 784 absorption wavelength of $398.67 \mathrm{~nm}, 819$ absorption wavelength of $295.46 \mathrm{~nm}, 369.21 \mathrm{~nm}$, TPO absorption wavelength of $294.67 \mathrm{~nm}$, $380.56 \mathrm{~nm}$, TPO-L absorption wavelength of $272.63 \mathrm{~nm}, 382.13 \mathrm{~nm}$, ITX absorption wavelength of $384.22 \mathrm{~nm}$, DETX absorption wavelength of $384.49 \mathrm{~nm} .784$ itself is orange in color and is very unstable. The formulated varnish stabilizes for about half an hour under indoor lighting in white light, so the 784 is not suitable for UV-LED curable printing inks or varnishes.ITX will migrate, contaminate the food in packaging,In 2005, Nestlé milk powder recalled 2 million liters of milk powder in the European market because of product packaging exuding ink (ITX), and one after another found some residuals in the drinks, but it was restricted in YQ69-2015.Therefore, the photoinitiator ITX can not be used a large number of in UV-LED curing varnish.DETX is forbidden to use in YQ692015, it can only be used in non-food packaging printing materials.TPO, TPO-L, 819 is a phosphine oxide photoinitiator with long absorption wavelength, good storage stability and little yellowing, so it is suitable for UV-LED curing varnish or ink.

\section{CONCLUSIONS}

Photoinitiators are a key component of UV-LED curing materials and play a decisive role in the cure rate of photo-curable materials, The development direction of photoinitiators are photoinitiators with high absorption intensity, large activity, shallow color, not yellowing, good solubility and low toxicity near $385 \mathrm{~nm}$ or $395 \mathrm{~nm}$ wavelength.The selected photoinitiators should be non-toxic to the human body, in line with the requirements of normative international legal documents on food safety,UV spectrum of the 12 common kinds of photoinitiators tested and analyzed showed that:Photoinitiators TPO, TPO-L, 819 can be used in UVLED curing varnish or ink and other light-curing materials.

\section{ACKNOWLEDGMENTS}

This study is funded by the Key Science and Technology Project of Beijing Municipal Education Commission (KZ201610015015), and by the National Key Scientific Instrument and Equipment Development Project (NO. 2013YQ140517).

Author : Bu Rongxia (1993-) , Female, Shandong Province, School of Printing and Packaging Engineering,E-mail:2572110646@qq.com Corresponding Author : Luo Shiyong (1967-) , male, professor, School of Printing and Packaging Engineering,Email:luoshiyong@bigc.edu.cn

\section{REFERENCES}

[1] Dongxu, S., Hongzhen, L., Tao, D., Yu, S.C. 2011. Research Progress of Photoinitiator Residue Analysis [J]. Rock and Mineral Testing, 30 (1), 104-109.

[2] Yi, Z. 2010. Study on the synthesis and properties of UV-Curable Waterborne Polyurethane Coatings [D]. South China University of Technology.

[3] Dietlin, C., Schweizer, S., Xiao, P., Zhang, J., Savary, F.M., Graff, B., Fouassiera, J.P., Lalevée, J. 2015. Photopolymerization upon LEDs: newphotoinitiating systems and strategies [J]. Polymer Chemistry, 6 (21), 3895-3912.

[4] Siegel, S.B. 2005. UV Commercialization of LED Curing [A]. Proceedings of RadTech Asia, 339-356. 2

[5] Shanshan, L., Wei, K., Ziyan, F., Zhonghao, L., Qinghua, W., Fei, Y., Zhaoyang, B., Duqing, F., Gangling, T. 2014. Research progress of photoinitiator residues and their migration in food contact materials [J]. Chinese Journal of Food Hygiene, 26 (05), 507-514.

[6] Youming, H. 2016. Single solvent system ink applications [J]. Chinese printing, (08), 67-68. 